\title{
NOTA SOBRE FIEBRE TIFOIDEA Y CLOROMICETINA (*)
}

\author{
Por el Dr. FIDEL URRUTIA \\ Hospital Clinico de Conoención. Sección Pediatria. Jele: Dr. Ratíl Ortega.
}

Desde 1945 a 1948 se atendieron en nuestro Servicio 110 casos de fiebre tifoidea $\mathrm{y}$ fallecieron $11(10 \%)$. En una segunda serie, que corresponde al año 1949 , recibimos 46 casos, en la mayoria de los cuales se ejerció especial vigilencia sobre la hidratación; en esta serie fallecieron 2 , es decir, una letalidad de $4,3 \%$, inferior por tanto a la anterior, pero sin significación estadística $\mathrm{x}$

$\left(\frac{1}{6}==1,18\right)$. Sin embargo, si no hubo disminución significativa en la letalidad, fué evidente que estos niños vieron transcurrir su enfermedad con mucho menos molestia.

\section{Cloromicetina.}

Ya en el curso de 1949 pudimos tratar algunos niños que consiguieron la droga. Nos referimos ahora a 45 casos tratados desde entonces. La edad fluctuaba entre 3 y 6 años en 21 , y entre 7 y 12 en 24. E1 diagnóstico se estableció por el curso clínico, la aglutinación (39 casos positivos), el hemocultivo (1 positivo entre 3 investigados), el urocultivo (positivo en 3 entre 36 examinados) y el hemograma y la sedimentación.

En promedio, los niños llevaban 10,3 días de enfermedad antes de administrar la droga, con 4 días en la evolución más corta y 30 en la más larga.

La fiebre cayó en lisis en 33 casos y en crisis en 12. En promedio duró 3,9

(*) L.a nusyor parte de la casuistica de este trabajo fué presentada a la Sociedad de Pediatria de Concepeión. Sesión del 17 de abril de 1951. días con una variación de 1 y 11 días; es de advertir que hubo sólo 1 caso con esta últime cifra, ya que todos los restantes cayeron en el curso de la primera semana. En 12 casos tratados en la primera semana de evolución de la enfermedad, la fiebre desapareció después de un promedio de 4,2 días; en 21 de segunda semana y en 12 de tercera o más, el niño quedó afebril después de 3,7 días. Hubo persistencia de febrículas en 9 casos.

En cuanto a gravedad, 4 eran leves, 23 de mediana gravedad y 18 graves.

Recidivas se produjeron en 3 casos, sin incidentes.

La diarrea cesó en 9 casos y se mantuvo en 9.

El título de Widal subió en 12, bajó o se mantuvo en 19, viró a negativo en 3.

Dosificación: Los primeros 6 casos fueron tratados con una dosis inicial de 1,5 g, seguida de $0,25 \mathrm{~g}$ cada 2-3-4 horas. La dosis inicial fué suprimida desde el $7^{9}$ caso, porque observamos que ella constituia una molestia para el niño y daba la impresión de que no acarreaba beneficios; continuamos, pues, administrando cada 2-3-4 horas, pero sin dosis inicial. En esta forma completamos, con Ios anteriores, 12 enfermos. En los 33 restantes optamos por distanciar los plazos, en forma que desde fines de 1950 damos $250 \mathrm{mg}$ cada 6 horas, sin consideración al peso ni a la edad del niño. La cantidad total -incluídos Ios casos con dosis inicial- fué, en promedio, $10,7 \mathrm{~g}$ (máximo 24 y mínimo 6). Actualmente se ensaya la administración de $250 \mathrm{mg}$ cada 8 horas. 
La duración del tratamiento en promedio fué de 9,9 días, 5 días en el más corto y 18 en el más largo.

Los dias de estada, 23,8. En la serie anterior, de 46 casos $\sin$ cloromicetina, fué de 33,8 días. Tenemos la impresión que no es posible acortar más la estada, pues la posibilidad de recidiva aconseja observar al niño en el Hospital por un tiempo prudencial. Debemos agregar, además, que en la segunda serie pudimos dar de alta 2 niños a los 13 días, en virtud de contar con la seguridad de una estricta vigilancia médica y reposo en cama en su domicilio.

Complicaciones: En 3 casos hubo compromiso cardiovascular de cierta importancia: estos niños no habían recibido dosis inicial y eran del grupo en que la droga se administró cada 6 horas. En 3 habia neumonia; en 1 , síndrome hemorragíparo de comienzo; en 1 , osteoartritis de la muñeca, que curó después de la cloromicetina; en 1, melena; en 1, panadizo y piuria en otro.

Tolerancia de la droga: Fué en general buena, salvo en un caso con presen- cia de vómitos persistentes, que obligaron a repetir la administración en varias oportunidades; este mismo caso es aquél a que ya nos referimos, en que la fiebre cayó sólo a los 11 días, lo que nos hace pensar ahora que posiblemente muchas dosis no fueron aprovechadas.

Mortalidad: No hemos tenido muertes en esta serie de 45 casos.

\section{Resumen.}

Cuarenta y cinco casos de fiebre tifoidea en niños de 3 a 12 años, tratados la mayoría, con $250 \mathrm{mg}$ de cloromicetina cada 6 horas, sin consideración al peso ni a la edad y sin dosis inicial. La letalidad fué nula y las complícaciones escasas.

\section{Summary.}

To 45 children, 3 to 12 years old, suffering typhoid fever, $250 \mathrm{mg}$ chloromycetin every 6 hours were administered without an initial dose. No deaths were observed. 